\title{
The Adsorption of Ions from Sea-Water by Sand.
}

\author{
By
}

\author{
F. P. Stowell, B.Sc., Ph.D., \\ Aquarium Research Fellow of the Zoological Society of London.
}

THE surface adsorption of molecules and ions of electrolytes by solid matter in a fine state of subdivision is a phenomenon of widespread and common occurrence in Nature, and its study an extremely important one. It plays a fundamental rôle in agricultural problems, the character of a soil being to a large extent governed by its adsorbing power for salts and non-electrolytes dissolved in the water which permeates it. From a technical point of view, its applications are numerous. The use of charcoal as a purifying agent is due to its high adsorptive power for impurities. The precipitation of colloids takes place through the adsorption of ions by them and the neutralisation of the electric charge they carry. The study of adsorption and its effects is a field in itself, and in the present paper only a brief résumé will be given, in introduction, of the subject of adsorption from solution.

Owing to the fact that adsorption is necessarily allied with surface effect, the study of adsorption phenomena is more or less confined to that branch of chemistry which deals with the physical and chemical effects of surface as opposed to mass. If any substance exists in a highly subdivided state, the surface presented is very large compared with the mass, and the laws governing the properties of surfaces come into play. All solids tend to condense or adsorb on their surface any gases, vapours, or ions in solution with which they may come into contact. Hence, when the surface of solid exposed is large compared with its mass, the tendency to adsorption, or surface condensation, is also very large. In the case of adsorption from solution, the possibility of adsorption of solvent must also be taken into account. If the adsorption of solute is greater than that of solvent, the adsorption is positive, the solution of necessity becoming more dilute; and, vice versa, negative adsorption results in a more concentrated solution, through preferential adsorption of solvent. When positive adsorption takes place from a solution containing more than one entity (such as a number of ions), the point arises as to what extent the adsorption is specific to each entity in the solution, that is, the extent to which the adsorption is selective. During research on the adsorption of various salts by blood charcoal, Osaka (1) found that the adsorption of 
anions with the same base decreased in the order $\mathrm{I}>\mathrm{NO}_{3}>\mathrm{Br}>\mathrm{Cl}>\mathrm{SO}_{4}$. Rona and Michaelis (2) state the order of adsorption of anions by charcoal to be $\mathrm{OH}>\mathrm{CNS}>\mathrm{I}>\mathrm{NO}_{3}>\mathrm{Br}>\mathrm{Cl}>\mathrm{HPO}_{4}>\mathrm{SO}_{4}$, and of cations $\mathrm{H}>\mathrm{Al}>\mathrm{Ca}>\mathrm{Zn}>\mathrm{Mg}>\mathrm{NH}_{4}>\mathrm{K}, \mathrm{Na}$. It should be mentioned that this adsorption order has been adversely criticised by Loeb (3), in his researches on protein adsorption, in which combination probably takes place according to the ordinary laws of primary and secondary valency. In the work of Rona and Michaelis, however, and in the present investigation, we are dealing with a simple inorganic adsorbing agent, and not a complex protein. Consequently, the adsorption depends on the mobility of the ion and the position in the electrolytic potential series, as well as on the valency (4).

Apart from the purely physical effects following upon adsorption, selective adsorption always connotes the possibility of chemical decomposition as a result of that adsorption. For example, if a substance adsorbs a base in preference to an acid, there will be a tendency for the salt of that base and acid to hydrolyse, the base then being adsorbed to a greater extent than the acid (5). Fuller's earth adsorbs the base from sodium chloride solution, rendering the filtrate acid to litmus. The well-known Permutit system of water softening is due to a chemical replacement of magnesium and calcium by sodium on filtration through specially prepared sands of the zeolite type.

Sea-water is a relatively complex solution containing the metallic ions sodium, potassium, magnesium, and calcium, and the anions sulphate, chloride and carbonate in more or less invariant proportions. It is a matter of interest, therefore, to investigate from the point of view of adsorption, the effect on the chemical and physical properties of such a solution, of percolation through and continued contact with sand, especially as the ions of calcium and magnesium, which are of recognised biological importance, are present in sea-water in a state of delicate equilibrium, so far as they exist as carbonate and bicarbonate, and, as shown by Atkins (6), require a relatively small alteration in $\mathrm{pH}$ to cause their partial precipitation.

Investigations of the salinity at various points in the circulation of the Zoological Society's Aquarium had revealed the interesting fact that a concentration of the saline constituents of the sea-water took place in the sand of the filter beds, where the water passes slowly through fine sand. The salinity in the filter beds (which was determined by carefully draining off a known volume of water from the sand and estimating the total solids at $180^{\circ} \mathrm{C}$.), was $37 \cdot 35$ per mille. The average salinity of the water in circulation at the time was $33 \cdot 7$ per mille.

A weighed amount of the wet sand was next dried in a steam oven, and the water driven off estimated by weight. Knowing the normal 
salinity of the water in use, it is easy to calculate the weight of solid matter which should be associated with it. The sand was then thoroughly washed with distilled water, and the total solids in the washings determined. In every case an increase in concentration was observed over the calculated normal value, due to positive adsorption by the sand particles. One instance is cited :-

From 116.423 grammes of wet sand, 17.4435 grammes of water were expelled. With this weight of water should be associated 0.6081 grammes of saline matter. Evaporation of the washings and estimation of the latter, however, indicated the presence of $0 \cdot 7840$ grammes of solid. This represents an increase in concentration of over 25 per cent. The point was further investigated by the author, and from the results of analysis, which are appended below, the conclusion was arrived at that this concentration was due to positive adsorption, brought about by the large surface exposed to the water by the sand particles.

\section{Specific Adsorption of the Constituent Ions of Sea-water.}

In the following experiments different varieties* of sand were used, but in order as far as possible to render the conditions of experimental procedure uniform, similar weights of each sand were employed in each. experiment, and equal volumes of sea-water. The sand was treated with hydrochloric acid to dissolve small fragments of shell and carbonate particles, and finally washed free from chlorides with distilled water and dried in an air oven.

The first method adopted was to allow a known volume of sea-water to stand in contact with the sand for twenty-four hours, with regular shaking at intervals, and the supernatant liquid was subsequently withdrawn and analysed. The method, however, gave no conclusive results, as the adsorption was either practically nil, or else water and saline matter were adsorbed in equivalent proportions. This was probably due to the fact that relatively large volumes of water must be used in comparison with the quantity of sand. A percolation method was next employed, which at once gave evidence of positive adsorption of solute. The samples of clean dry sand were contained in glass jars provided with

\footnotetext{
* Experiments I and II were conducted with the original sample of sand from the Aquarium filter beds. This is a river sand from Leighton Buzzard, which has been in continuous contact with the sea-water for over two years. The sample in Experiment III was a marine sand collected in June, 1926, from the low tidal area of Port Erin bay, I.O.M. Experiment IV was undertaken with a fine silver sand on the high-water mark of Douglas beach, I.O.M., collected in June, 1926. Experiments were also conducted, the results of which are not given here, as they simply confirm the present ones, on another marine sand, the exact locality of which is not known, and on a fine silver sand from Bedfordshire. Unfortunately no samples have been obtained from the ocean bed, but it is unlikely that the results would differ appreciably from the samples studied, save perhaps in the extent of adsorption.
} 
suitable outlets at the base, and sea-water allowed to spray over the surface at the rate of approximately 250 c.c. per hour. The filtrate was collected in fractions of 100 c.c., and submitted to analysis. Since the accurate estimation of calcium in the presence of magnesium is somewhat difficult, owing to the occlusion of magnesium in the calcium precipitate on separation, double precipitation of the calcium was carried out in the presence of ammonium citrate, according to the method employed by the author ( $\mathbf{y})$ in previous analyses. The estimation of the remaining constituents was carried out by the ordinary methods of inorganic analysis.

In all the cases investigated, percolation through sand was found to bring about a positive adsorption of solute, though the extent in many cases varied considerably with the sample of sand, and the volume of water filtered. Taken as a whole, the extent of the adsorption could not be termed very large, save in two cases, which are cited below (Tables III and IV). Though the amount of total adsorption differed, however, in every case, the individual adsorption of the constituent ions was specific, and was found to be a factor of the concentration, with the exception of the calcium and magnesium ions, which exhibited an abnormality which could only be accounted for by a chemical interaction and exchange of ions with the " active " adsorbing agent. A few representative experiments are given below.

\section{Experiment $I$.}

Sea-water of salinity $34 \cdot 71$ per mille was allowed to percolate through sand, and the first 500 c.c. of percolate collected and analysed. The $\mathrm{pH}$ before the experiment was $8 \cdot 1 . *$ and after percolation $7 \cdot 9$.

\section{TABLE I.}

\begin{tabular}{|c|c|c|c|}
\hline \multicolumn{2}{|c|}{$\begin{array}{l}\text { Ion Constituent. } \\
\text { Sodium and Potassium }\end{array}$} & $\begin{array}{l}\text { Sample before } \\
\text { treatment. } \\
10.91\end{array}$ & $\begin{array}{l}\text { Sample after } \\
\text { percolation. } \\
10 \cdot 47\end{array}$ \\
\hline Magnesium & . & $1 \cdot 392$ & $1 \cdot 221$ \\
\hline Calcium . & . & $0 \cdot 4002$ & $0 \cdot 4 \geq 00$ \\
\hline Sulphate & . & $2 \cdot 632$ & $2 \cdot 463$ \\
\hline Bicarbonate & . & $0 \cdot 1500$ & $0 \cdot 1460$ \\
\hline Chloride & . & . $19 \cdot 23$ & $18 \cdot 04$ \\
\hline & & & $32 \cdot$ \\
\hline
\end{tabular}

It will be observed that although the total adsorption is not large, all the constituent ions have undergone a more or less proportional individual adsorption, with the exception of calcium and magnesium, which exhibit abnormality, the concentration of calcium in the percolate,

\footnotetext{
* Corrected for salt error
} 
in fact, being greater than in the original solution. The abnormality is more clearly brought out in Table II, which is a comparison of the actual results obtained, with those calculated on the basis of an adsorption of each constituent ion in the proportion equivalent to the total adsorption, i.e.

$$
\mathrm{C}_{\text {cale. }}=\text { Original concentration } \times\left(\frac{32 \cdot 75}{34 \cdot 71}\right)
$$

TABLE II.

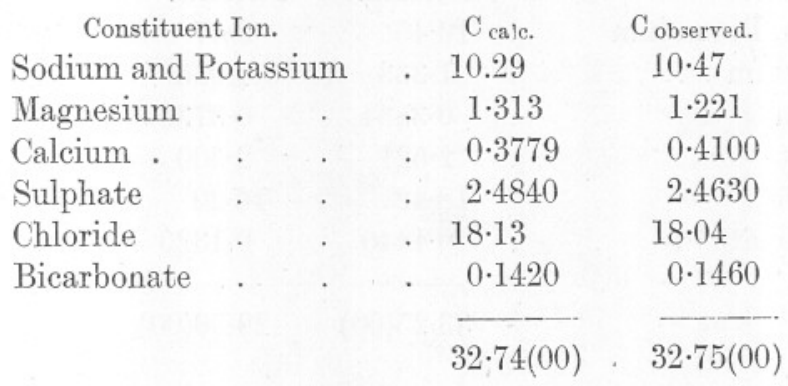

\section{Experiment II.}

The rate of percolation and other conditions of experiment were unaltered, but only the first 100 c.c. of the percolate were collected and analysed. The $\mathrm{pH}$ remained practically unaltered throughout the experiment.

\section{TABLE III.}

\begin{tabular}{|c|c|c|c|c|}
\hline \multicolumn{2}{|c|}{$\begin{array}{l}\text { Ion Constituent. } \\
\text { Sodium and Potassium }\end{array}$} & $\begin{array}{c}\text { Sample before } \\
\text { treatment. } \\
\quad 10 \cdot 91\end{array}$ & $\begin{array}{l}\text { Percolate. } \\
9 \cdot 51\end{array}$ & $\begin{array}{l}\mathrm{C}_{\text {ca'c. }} \\
9 \cdot 22\end{array}$ \\
\hline Magnesium & . & . 1.392 & $1 \cdot 070$ & $1 \cdot 176$ \\
\hline Calcium & . & $0 \cdot 4002$ & $0 \cdot 3921$ & $0 \cdot 3382$ \\
\hline Chloride & . & . $19 \cdot 23$ & $15 \cdot 96$ & $16 \cdot 25$ \\
\hline Sulphate & . & $2 \cdot 632$ & $2 \cdot 270$ & $2 \cdot 224$ \\
\hline Bicarbonate & . & $0 \cdot 1500$ & $0 \cdot 1260$ & $0 \cdot 1270$ \\
\hline & & $34 \cdot 71(00)$ & $29 \cdot 33(00)$ & 2 \\
\hline
\end{tabular}

In the present case the extent of total adsorption is over 15 per cent. Each constituent ion has been adsorbed, and the agreement between $\mathrm{C}_{\text {observed }}$ and $\mathrm{C}_{\text {calc. }}$ is fairly good in the case of sodium and potassium, sulphate, chloride and bicarbonate ions; but differs appreciably for calcium and magnesium, the observed value for the former being much too high, and the latter apparently having undergone a greater adsorption than the remaining ions. 
Experiment $I I I$.

A sample of fine marine sand was employed, and sea-water of a slightly lower salinity was allowed to percolate through at the rate of about 250 c.c. per hour. The first 100 c.c. were submitted to analysis.

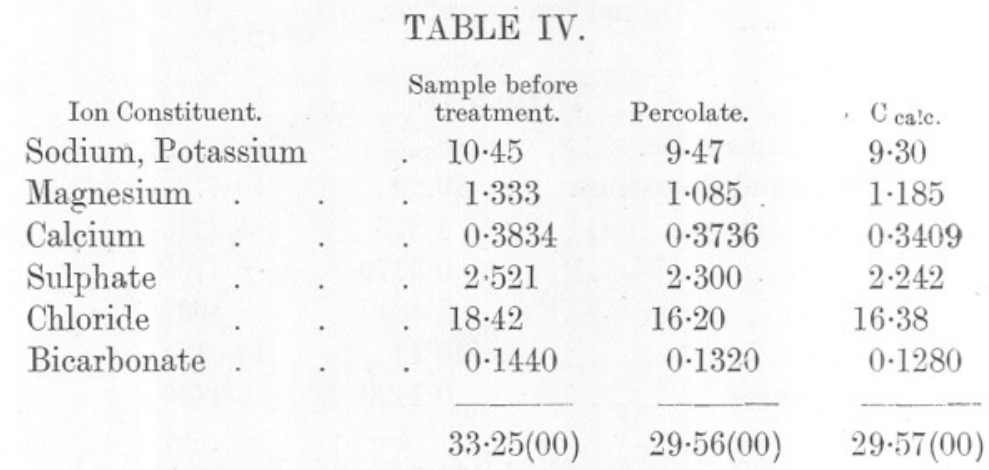

The results offer a close parallel with those obtaining in the previous experiment. The $\mathrm{pH}$ altered from 8.0 to $7 \cdot 7$, indicating a trifle more acidity.

\section{Experiment $I V$.}

The same procedure was adopted as in the previous experiments, but the sample of sand employed adsorbed very little of the constituent electrolytes in the water. The results of analysis are important, however, as the same phenomenon was observable in the case of calcium and magnesium as in the previous cases, the concentration of calcium in the percolate, in fact, being higher than in the original solution.

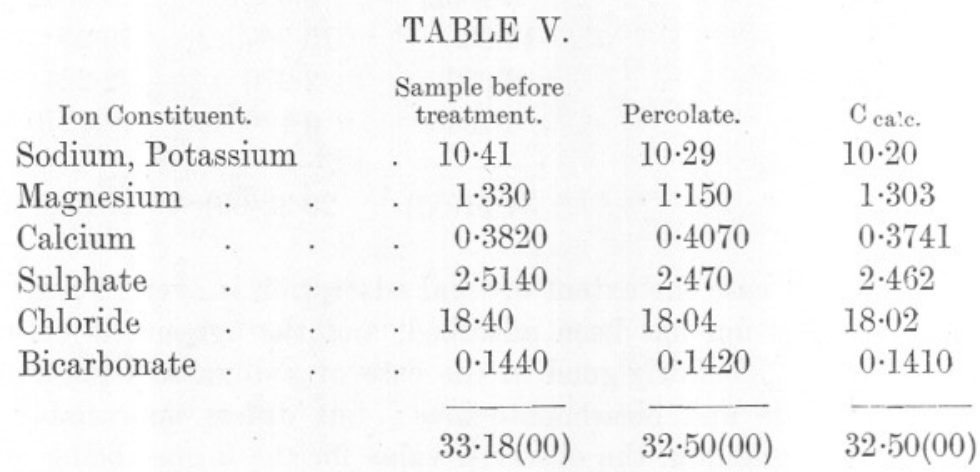




\section{DISCUSSION OF RESULTS.}

In the preceding tables, a comparison between the concentrations of each constituent ion after percolation and the concentrations calculated on the basis of a proportional adsorption of each ion, that is, between $\mathrm{C}_{\text {actual }}$ and $\mathrm{C}_{\text {calc. }}$ indicates the comparative normality in the adsorption of sodium and potassium, sulphate and chloride ions, the discrepancy apparently lying between the ions of calcium and magnesium. Since the concentrations of the respective ions in sea-water are widely divergent, it is unlikely that the order of physical adsorption of the ions (in the absence of chemical interaction with an active adsorbing agent) will more than approximate to that of Rona and Michaelis (loc. cit.). If, however, the adsorption be purely physical, it is dependent on $a$ the concentration of the adsorbed ion, $b$ the nature and amount of the adsorbing agent, $c$ the temperature, and $d$ the rate of percolation; $b, c$, and $d$ are constant throughout each experiment. Hence it is possible by dividing the amount of adsorption, $x$, of each constituent ion, by its concentration, $c$, to obtain a rough measure of the order of adsorption of the ions in sea-water, and to compare the order obtained with that of Michaelis and Rona. The ratio $\mathrm{x} / \mathrm{a}$ is given in the following table.

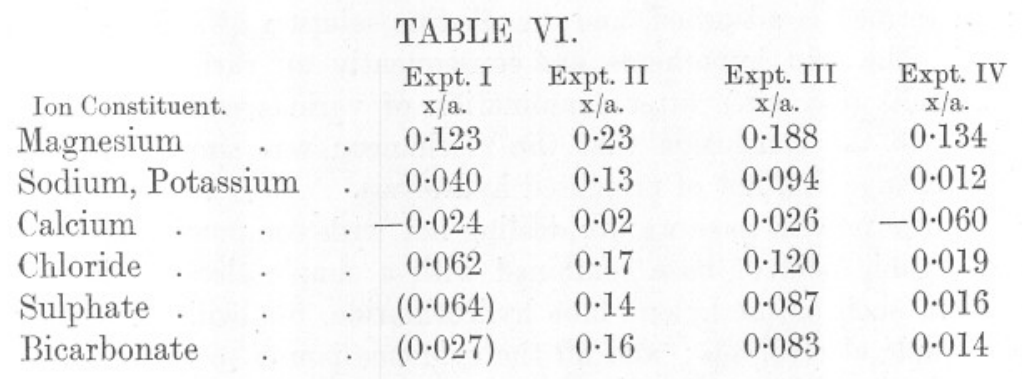

It is apparent from the above table that the order of adsorption is the same in each case, viz. $\mathrm{Mg}>\mathrm{Na}, \mathrm{K}>\mathrm{Ca}$, and $\mathrm{Cl}>\mathrm{SO}_{4}, \mathrm{HCO}_{3}$. For the anions, this is in agreement with the observations of Rona and Michaelis (loc. cit.) on the adsorption by charcoal of anions attached to the same cation. The rule breaks down with the cations, however; Rona and Michaelis finding the order $\mathrm{Ca}>\mathrm{Zn}>\mathrm{Mg}>\mathrm{NH}_{4}>\mathrm{K}, \mathrm{Na}$. We find in the present case that the calcium ion is adsorbed to a far less extent than magnesium ion. In sea-water, both these ions exist in combination. with the same anions - chloride and carbonate - and, to a less extent, with sulphate ion, hence the rule of Rona and Michaelis should hold, if the adsorbing agent were inert.

It must be remembered, however, that the work of Rona and Michaelis was undertaken with charcoal as the adsorbing agent. Charcoal may 
be termed inert, in so far as it is incapable of discharging any ions into the solution in contact with it. Many adsorbing agents, it is well known, are active, and can discharge into solution either anions or cations. In this case ionic adsorption and interchange take place. As an example may be cited the absorption of methylene blue hydrochloride by silicates :-

Calcium silicate + methylene blue hydrochloride $=$ methylene blue silicate + calcium chloride,

the net result being the replacement of one base by another and the passage into solution of calcium as calcium chloride. The interaction between Fuller's earth and neutral sodium chloride solution, already mentioned, is also relevant, on account of the alternative theory of Bancroft (8) to the hypothesis of ionic interchange. The sodium ions in the solution adsorbed by the Fuller's earth have, according to Michaelis, been replaced by hydrogen ions from the earth, as the indirect result of the liberation of calcium ions. According to Bancroft, if a salt undergo hydrolysis in solution, according to the equation :-

$$
\mathrm{M}+\mathrm{X}^{\prime}+\mathrm{H}_{2} \mathrm{O} \rightleftharpoons \mathrm{M}+\mathrm{OH}^{\prime}+\mathrm{X}^{\prime}+\mathrm{H}^{\prime} \text {, }
$$

and the acid $\mathrm{H}^{\prime} \mathrm{X}^{\prime}$ is selectively adsorbed, hydrolysis will proceed until equilibrium is attained. In the case of Fuller's earth, the hydrochloric acid formed is adsorbed, and an alkaline solution of sodium hydroxide left. The two hypotheses are consequently at variance. Rona and Michaelis (loc. cit.), after examination of various cases of adsorption, came to the conclusion that the mechanism was simply one of ionic interchange and not of promoted hydrolysis.

In the present case we are dealing not with compounds consisting of an organic acid or base combined with a simple electrolytic anion or cation, such as methylene blue hydrochloride, but with the adsorption of simple electrolytes; and all the evidence points to the fact that the adsorbing medium is not in all probability an inert one, and if Bancroft's theory is correct, the possibility remains of a promoted hydrolysis in sea-water following adsorption. On the other hand, the mechanism may be one of adsorption accompanied by simple ionic exchange.

It is obvious from the results that whereas the remainder of the ions in the sea-water have undergone simple physical adsorption, the calcium and magnesium have entered into a chemical reaction. Promoted hydrolysis has evidently not taken place, as the liberated $\mathrm{H}^{\prime}$ ions or $\mathrm{OH}^{\prime}$ ions would render the fact apparent by the change of acidity of the percolate. The $\mathrm{pH}$ of the solution, however, has not changed sufficiently to warrant the conclusion that hydrolysis is appreciable. It seems certain, therefore, that the relatively small adsorption of calcium ion from the sea-water is due to ionic exchange between magnesium and the calcium salts contained in the sand ( $\mathbf{y})$. In order to investigate the mechanism more closely 
experiments were carried out on the adsorption of each constituent ion from separate solutions containing the ion in the absence of the remainder. Each solution was made up of such a strength that the ion under investigation was present in roughly the same concentration as in sea-water. The first 100 c.c. of the solution was collected after percolation under the same conditions as before.

\section{Sodium and Chloride Ions.}

Since these ions form by far the largest portion of the ionic constituents of sea-water, and exist in it as sodium chloride, a solution of the latter was used of strength 26.66 grammes per litre. The total solids were estimated before and after percolation, the chloride ion determined by titration with standard silver nitrate solution, and the sodium by conversion into sulphate. Analysis also showed the presence of calcium in the percolate.

\begin{tabular}{|c|c|c|c|}
\hline Constituent. & $\begin{array}{l}\text { Concn. in gm. } \\
\text { per litre before } \\
\text { percolation. }\end{array}$ & $\begin{array}{l}\text { Concn. in gm. } \\
\text { per litre after } \\
\text { treatment. }\end{array}$ & $\mathrm{C}_{\text {cale. }}$ \\
\hline Sodium & . $\quad 10 \cdot 48$ & $8 \cdot 63$ & $8 \cdot 62$ \\
\hline Chloride & $16 \cdot 17$ & $13 \cdot 24$ & $13 \cdot 30$ \\
\hline Calcium & - & 0.065 & - \\
\hline Total Solid & $26 \cdot 65$ & 21.935 & $21 \cdot 92$ \\
\hline
\end{tabular}

\section{Magnesium.}

A solution of magnesium sulphate was employed containing a concentration of magnesium ions of 1.412 grammes (approx.) per litre of solution, and submitted to treatment. The concentrations of magnesium ions before and after the experiment were respectively 1.413 and $1 \cdot 139$ grammes per litre. A positive adsorption had consequently taken place of 0.274 grammes per litre. Calcium was also found in the percolate in the concentration of 0.0725 grammes per litre.

\section{Sulphate IoN.}

Magnesium sulphate solution was again employed, of such strength that the sulphate concentration was 2.632 grammes per litre. After percolation the concentration was $2 \cdot 213$ grammes per litre, indicating a positive adsorption of 0.419 grammes per litre of solution.

\section{Calcium Ion.}

A solution of calcium chloride containing 0.403 grammes of calcium per litre was submitted to percolation. The calcium ion concentration by analysis before and after the experiment was estimated as 0.401 grammes and 0.383 grammes per litre respectively. Positive adsorption therefore takes place from a solution of pure calcium chloride. 


\section{Bicarbonate Ion.}

Since practically all the excess base in sea-water exists as bicarbonate, the results in the preceding tables have been expressed as such, the actual carbonate ion being negligible. It is somewhat difficult to reproduce in individual solution the delicate balance of calcium and magnesium bicarbonates as they exist in sea-water; but by making up a solution of magnesium sulphate, calcium chloride, and a few drops of sodium carbonate, saturating with carbon dioxide gas, and, finally, removing the excess of the latter by blowing air through the solution, a medium of $\mathrm{pH} 7.7$ was obtained. The bicarbonate was estimated before and after percolation by titration with $0.01 \mathrm{~N}$ hydrochloric acid, using bromocresol purple as indicator, and the concentrations found to be $0 \cdot 1606$ and $0 \cdot 1411$ grammes per litre respectively.

The ratio $\mathrm{x} / \mathrm{a}$ has been calculated for the adsorption from individual solution, and the order of adsorption agrees with that found for sea-water viz. $\mathrm{Mg}(0 \cdot 19)>\mathrm{Na}, \mathrm{K}(0 \cdot 13)>\mathrm{Ca}(0 \cdot 045)$; and $\mathrm{Cl}(0 \cdot 18)>\mathrm{SO}_{4}(0 \cdot 16)>\mathrm{HCO}_{3}$ $(0 \cdot 12)$. From the experimental data it is seen that individual solutions containing sodium and magnesium carry down with them calcium ion, the larger proportion being attributable to the magnesium. On account of the relatively high concentration of sodium chloride in sea-water, the small exchange with sodium is scarcely noticeable from the alteration in the concentration of sodium ion, but is easily detectable in the case of magnesium. If the amount of calcium brought down with sodium and magnesium be subtracted from the concentration of calcium found in the percolate, calcium assumes its proper position in the adsorption order of Rona and Michaelis. The cases cited above are representative of a number of experiments carried out on various sands; in every sample examined the concentration of calcium ion in the percolate was decidedly in excess of the calculated value ; in fact, where the adsorption of the remaining ions was practically nil, the concentration of calcium ion was in excess of that in the original sea-water sample. Magnesium was invariably low. This exchange does not cease when the adsorption of the remaining salts has reached a limit. It cannot be due to the solution of particles of calcium carbonate in the sand, as the preliminary treatment of the sand with acid removes these. Sands, however, contain a certain quantity of silicates and alumino-silicates of calcium (9), and it is extremely probable that it is with these radicles that the exchange takes place, after the following manner:-

Calcium ortho-silicate

$\left.\begin{array}{l}\text { Calcium meta-silicate } \\ \text { Calcium alumino-silicate }\end{array}\right\}+$ sodium chloride $=\left\{\begin{array}{l}\text { Sodium ortho-silicate } \\ \text { Sodium meta-silicate } \\ \text { Sodium alumino-silicate }\end{array}\right.$ + calcium chloride. 
Calcium ortho-silicate

Calcium meta-silicate

Calcium alumino-silicate

Calcium o-silicate

Calcium m-silicate

Calcium al-silicate I

$$
\begin{gathered}
=\left\{\begin{array}{l}
\text { Magnesium o-silicate } \\
\text { Magnesium m-silicate } \\
\text { Magnesium al-silicate }
\end{array}\right. \\
\quad \text { +calcium chloride. }
\end{gathered}
$$

The hydrolysis of the calcium chloride formed is very slight, and the quantity brought down small, hence the alteration in $\mathrm{pH}$ of the solution is also very slight, especially as the buffer action of sea-water is large on account of its bicarbonate content.

Summarising, the results show that the adsorption of the electrolytic constituents of sea-water by sand is small, and is perfectly normal, with the exception of a small basic exchange between calcium and magnesium. Though the results perhaps have more interest from a chemical point of view than a biological one, they have doubtless a slight bearing on the delicate calcium-magnesium-bicarbonate ratio in sea-water, which constitutes the alkaline reserve, and may be one of the contributory causes of the deposition of calcium carbonate by inorganic processes, as opposed to biological. Just as the addition of carbonate ion to a saturated solution of calcium carbonate in presence of solid calcium carbonate will precipitate the latter, the addition of calcium ion will have the same effect. This will be seen by the following line of argument :By the Law of Mass Action

$$
\frac{[\mathrm{Ca}]\left[\mathrm{CO}_{3}\right]}{\left[\mathrm{CaCO}_{3}\right]}=\mathrm{K}
$$

Since in presence of solid calcium carbonate $\left[\mathrm{CaCO}_{3}\right]$ is a constant,

$$
[\mathrm{Ca}]\left[\mathrm{CO}_{3}\right]=\mathrm{K}_{1} \text {. }
$$

Any addition of calcium ion to the solution will cause a corresponding depression in the concentration of $\mathrm{CO}_{3}$ ion, in order to keep the solubility product constant. This can only be effected by the precipitation of calcium carbonate. In tropical waters, for example, where the $\mathrm{pH}$ is high, and calcium carbonate is already present as coral or other calcareous deposit, a very slight increase in calcium ion concentration of the water by contact with and constant percolation through sand will cause a corresponding amount of precipitation of calcium carbonate from the water. The amount precipitated in this manner may be very small, but it is probably one of the indirect causes of inorganic deposition of calcium carbonate. In temperate zones, however, for large bulks of water, the adsorption and exchange is too small to cause any appreciable difference in the concentrations of calcium and magnesium in the water, and certainly does not promote sufficient hydrolysis to alter the $\mathrm{pH}$ of the medium unduly.

The adsorption of small variable constituents such as silicate and NEW SEries. vol. Xiv. No. 4. MAT, 1927. 
phosphate is of importance, as the concentrations of these ions in ocean waters may be correlated with the seasonal variations in diatom and plankton crops (10). The work is at present under investigation.

In conclusion, the author wishes to express his indebtedness to Dr. P. Chalmers Mitchell, Secretary of the Zoological Society, for helpful suggestions and advice on the subject.

\section{SUMMARY.}

1. The ions present in sea-water are normally adsorbed by sand.

2. Percolation of sea-water through sand causes a slight abnormality in the concentrations of calcium and magnesium ions, due to the fact that sand is not an inert adsorbing agent, but is capable of discharging calcium ions into the water in exchange for magnesium and sodium.

3. The extent of adsorption and exchange is insufficient to cause hydrolysis and alteration in $\mathrm{pH}$ if the bulk of the sea-water is large.

\section{REFERENCES.}

1. Osaka, Yukichi. On the Adsorption of Strong Electrolytes. Mem. Coll. Sci., Koyoto Univ., 1 (1915).

2. Rona, P. and Michaelis, L. Uber die Adsorption von Elektrolyten durch Kohle. Biochem. Zeit., 94, 240 (1919). Uber die Adsorption der $\mathrm{H}$ und $\mathrm{OH}$ Ionen und der Schwermetallionen durch Kohle, ibid., 97, 85 (1920).

3. Lowb, J. Proteins and the Theory of Colloidal Behaviour (McGrawHill Book Co., New York, 1924).

4. Rideal, E. K. An Introduction to Surface Chemistry (Cambridge University Press, 1926), pp. 185 seq.

5. Rideal, E. K. An Introduction to Surface Chemistry, p. 188.

6. Atkins, W. R. G. The Hydrogen Ion Concentration of Sea-water. Jour. Mar. Biol. Assoc., 12, 717 (1919).

7. Stowell, F. P. Physical and Chemical Conditions in the Fresh Water Circulation of the Society's Aquarium. Proc. Zool. Soc. of London, 1927, Part I, pp. 19 seq.

8. Bancroft, W. D. Report on Peptisation and Precipitation. Brit. Assoc., Second Colloid Report (1918).

9. Searle, A. B. Sands and Crushed Rocks (Oxford Tech. Pubn., 1).

10. Atkins, W. R. G. Phosphate Content of Fresh and Salt Waters and Growth of Algal Plankton. Jour. Mar. Biol. Assoc., 13 (1923), p. 119. The Silica Content of some Natural Waters, ibid. 13 (1923), p. 151. 